\title{
The landscape of immune checkpoints expression in non-small cell lung cancer: a narrative review
}

\author{
Yu Liu ${ }^{1,2 \#}$, Peixin Chen ${ }^{1,2 \#}$, Hao Wang ${ }^{1,2}$, Shengyu Wu ${ }^{1,2}$, Sha Zhao ${ }^{1,2}$, Yayi He ${ }^{1}$, Caicun Zhou ${ }^{1}$, \\ Fred R. Hirsch ${ }^{3}$ \\ ${ }^{1}$ Department of Medical Oncology, Shanghai Pulmonary Hospital, Shanghai, China; ${ }^{2}$ School of Medicine, Tongji University, Shanghai, China; \\ ${ }^{3}$ Center for Thoracic Oncology, Mount Sinai Cancer, New York, NY, USA \\ Contributions: (I) Conception and design: Y He, C Zhou, FR Hirsch; (II) Administrative support: C Zhou; (III) Provision of study materials or \\ patients: Y He, FR Hirsch; (IV) Collection and assembly of data: Y Liu, H Wang, S Zhao; (V) Data analysis and interpretation: Y Liu, P Chen, S \\ Wu; (VI) Manuscript writing: All authors; (VII) Final approval of manuscript: All authors. \\ \#These authors contributed equally to this work. \\ Correspondence to: Caicun Zhou; Yayi He. Department of Medical Oncology, Shanghai Pulmonary Hospital, Shanghai 200433, China. \\ Email: caicunzhoudr@126.com; 2250601@qq.com.
}

\begin{abstract}
With the increasing clinical potential of tumor immunotherapy, more and more clinical trials are undergoing with immune checkpoint inhibitors (ICIs). Immune checkpoints (ICs) have been identified as crucial regulators of the immune response and have improved ICIs-inhibitor therapeutic strategies. The most important ICs in lung cancer include programmed cell death-1 (PD-1), programmed cell death ligand-1 (PD-L1), lymphocyte activation gene-3 (LAG-3), major histocompatibility complex class II (MHC II), T cell immunoglobulin and mucin-domain containing-3 (TIM-3), and Galectin-9 (GAL-9), OX-40, OX40L. However, the expression and prognostic value of these ICs are still controversial. Among them, high expression of PD-L1 on tumor cells (>50\%) predicts a better therapeutic effect of anti-PD-1 monoclonal antibody compared to patients with low PD-L1 expression. However, only 20-30\% of nonsmall cell lung cancer (NSCLC) patients seem to get benefit from immunotherapy. In order to improve the immunotherapy outcomes, more and more attention is paid to combination immunotherapy. Analyzing the co-expression of ICs can give us a more comprehensive basis for combination immunotherapy. This review article summarized our comprehensive expression of ICs based on our previous research, and analyzed their correlation with prognosis in NSCLC patients. We also provided suggestions for potentially personalized combination immunotherapy in NSCLC.
\end{abstract}

Keywords: Immune checkpoints (ICs); prognosis; non-small cell lung cancer (NSCLC); combination immunotherapy

Submitted Sep 05, 2020. Accepted for publication Dec 20, 2020.

doi: $10.21037 /$ tlcr-20-1019

View this article at: http://dx.doi.org/10.21037/tlcr-20-1019

\section{Introduction}

There were 2.1 million new lung cancer cases worldwide, accounting for $11.6 \%$ of all new cancer cases. With 1.8 million deaths, accounting for $18.4 \%$ of all cancer deaths, the incidence of lung cancer ranked first among all cancers in most countries and continues to rise (1). The five-year survival rate for lung cancer is $4-17 \%$, and about $80 \%$ of lung cancer patients are non-small cell lung cancer (NSCLC) (2). Nowadays, surgical treatment is still the primary method for early-stage lung cancer (3). Most patients are diagnosed too late for being surgical candidates with a relatively lower chance of long-term survival or cure. Chemotherapy has been an important role in the treatment of advanced NSCLC, but its five-year survival rate is only $5 \%$ (4). Targeted therapy has a good therapeutic outcome, 
but drug resistance is unavoidable in most patients and many patients do not have proper gene mutations for specific targeted therapy. Cancer immunotherapy has been a promising therapy nowadays (5).

Cancer immunotherapy depends on activating $\mathrm{T}$ cells from inhibitory status and functional exhaustion to eliminate tumor cells, which could be promoted by some tumor-infiltrating lymphocytes (TILs). However, a variety of lymphocytes, as a kind of infiltrating immune cells in cancers, could attack cancer cells or promote the immune escape of cancer cells $(6,7)$. Additionally, abnormal expression of immune checkpoint (ICs) molecules is one of the mechanisms of tumor immune escape. The basic principle of tumor immunotherapy is to apply immune checkpoint inhibitors (ICIs) to block the transmission of inhibitory signals and thereby induce an anti-tumor effect. Some ICs of tumors will inhibit $\mathrm{T}$ cell proliferation or antitumor activity, so the expression of the ICs will be directly associated with tumor immune escape. As recently reported in the literature, tumor cell-intrinsic programmed cell death-1 (PD-1)/programmed cell death ligand-1 (PD-L1) could suppress the canonical signaling pathways, regulate tumor growth, and mediate the resistance to the treatment with antiPD-1/PD-L1 antibodies (8). Therefore, the expression of ICs and TILs is crucial to cancer immunotherapy.

PD-1 and PD-L1 inhibitors have shown encouraging results in NSCLC and other cancers. They have been approved by the U.S. Food and Drug Administration (FDA) for the treatment of advanced NSCLC (9-13). Lymphocyte activation gene-3 (LAG-3), as a co-inhibitory molecule of $\mathrm{PD}-1$, has been proved to play a role in immune escape in various tumors $(14,15)$. Since the activation of antigenspecific CD4+ $\mathrm{T}$ cells requires the presence of major histocompatibility complex class II (MHC II) antigens, MHC II is important in anti-tumor immunity $(16,17)$. $\mathrm{T}$ cell immunoglobulin and mucin-domain containing-3 (TIM-3) is considered to be a negative regulator of CD4+ $\mathrm{T}$ cells and CD8+ T cells (18). Galectin-9 (GAL-9) also plays the role of manipulating the $\mathrm{T}$ effector immune cells and predicting the survival of patients with LAG-3 and TIM-3 (19,20). OX40 (CD134) has been shown to rebuild and enforce the weakened immune system and combat malignant cells $(21,22)$.

Many studies showed that the expression of ICs conveyed prognostic and predictive information $(2,6,23)$. Identifying patients who might get the benefits from immunotherapy will protect patients from unnecessary treatments and side effects. However, the accurate prognostic biomarkers of these ICs in NSCLC remain controversial. In this study, we reviewed several important ICs in NSCLC from our published paper $(9,14,16,17,20-22,24-26)$, including the frequency and co-expression of ICs. The goal of this review is to give an overall demonstration of the expression of ICs and the correlation with prognosis in NSCLC and to suggest some potentially personalized combination immunotherapies in NSCLC.

We present the study in accordance with the Narrative Review Checklist (Available at http://dx.doi.org/10.21037/ tlcr-20-1019).

\section{Correlation between ICs and clinical pathological factors in NSCLC}

Immunological factors are not only statistically related to some clinically pathological factors, but also functionally interact with each other in NSCLC. In this review, the reported immunological factors are potentially important for the immune regulation in NSCLC. ICs correlate with other ICs. LAG-3 has been reported as a clinically important immunological factor in various kinds of tumors (27-29). In breast cancer, Saleh et al. (30) not only found that tumor cells could affect the expression of LAG-3, PD-1, and TIM-3 but also illustrated that the status of PD-1 and PD-L1 further influenced the expression of TIM-3 and LAG-3 on TILs. Datar et al. (31) found that the distinct tissue/cell distribution of PD-1, LAG-3, and TIM-3, and their interaction results, which concluded that their immune evasion pathways were independent. Both tumors and TILs have an expression of MHC II (32-34). In gastric carcinomas, Ma et al. (35) found that the expression of MHC II was related to the differentiation of tumor and TILs. In lung cancer, the impairment of MHCDR expression was reported as one of the major reasons for immunosuppression (36). GAL-9, a member of the betagalactoside-binding animal lectin family, participates in various cellular biological events, while its function as the immunological factor was paradoxical. In hepatocellular carcinoma (HCC), Fujita et al. (37) found that the expression of GAL-9 led to the apoptosis of HCC cells, which was also reported in other malignancies $(38,39)$. However, GAL-9 was found to be suppressed by the autoimmune response as well (40). OX40 was recognized as the potential target for cancer immunotherapy (41). In advanced colorectal cancer, the expression of OX40 was reported to be related to the blood levels of other biomarkers, including PD-L1 (42). However, data on the expression of these ICs and their correlation with other clinically pathological factors in NSCLC are incomplete. We first reviewed the characteristics of potential immune 
biomarkers of NSCLC patients, which including PD-1, PDL1, LAG-3, MHC II, TIM-3, GAL-9, OX40, and OX40L (In our published paper, 3 patients were not stained with GAL-9 on tumor cells or TILs (20). We re-stained the GAL-9 in these 3 patients and got a negative result.

It was reported that the expression of OX40 on TILs was significantly correlated to smoking status, lung cancer pathology, and percentage of TILs (21). Besides, lung cancer pathology was significantly correlated to the expression of LAG-3 on TILs (14) and MHC II on tumors (16). Likewise, the lung cancer stage was correlated to the expression of OX40L on tumors (21), PD-L1 on tumors (9), MHC II on TILs (16). GAL-9 on tumors was the only ICs that had a significant correlation with the grade (20). However, there was no significant correlation among clinical-pathological factors and the expression of OX40 in tumors, PD-L1 on tumors, GAL-9 on TILs, TIM-3 on tumors, and TIM-3 on TILs $(9,20,21,26)$. Table 1 provided the detailed information of various ICs in NSCLC and their correlation with clinic pathological factors and other ICs, indicating that the smoking status, lung cancer pathology, stage, grade, metastasis, and TILs percentage were worthy of clinical attention as the complicated relationship between these factors and the status of ICs. Having a better understanding of the relationship between clinical factors and ICs can help us have more information on ICIs treatment and predict the disease progression of NSCLC patients.

\section{The landscape of ICs in NSCLC}

The innovative uses of the Upset and Venn plot help comprehend the relationship between these biomarkers clearly and comprehensively (Figure 1). Our review demonstrated that the positive status of different ICs could be variable in NSCLC patients.

Comparative analysis was carried out with Bioinformatics and Evolutionary Genomics tool (http://bioinformatics. psb.ugent.be/webtools/Venn/) and TBtools (43). The Upset plot showed the distribution of each IC in NSCLC. The bar graph above showed the number of ICs contained in each type of ICs group. The yellow bar graph at the bottom left showed the number of ICs contained in each type of ICs. Figure 1 demonstrated the co-expression of ICs in NSCLC and TILs in upset plot or Venn plot. According to the Upset plot and Venn plot below, a substantial proportion $(76.5 \%)$ of patients had a unique ICs combination. Unlike the mutually exclusive NSCLC driver genes, these figures indicated that co-expression of ICs was widespread, suggesting that immunotherapy combination may have a promising future. Table 2 and Figure 2 showed the distribution of multiple ICs positive patients. According to the pie chart, the ICs were not mutually exclusive, most patients $(82.0 \%)$ have 1 to 6 positive ICs, and only $7(5.0 \%)$ patients had no ICs expression. OX40L on TILs and OX40 on tumors were the top two high expressions in ICs and patients usually expressed them simultaneously, which might suggest that the combination therapy using these two target drugs may benefit patients to a large extent.

In this pie chart (Figure 2), it showed the number of positive ICs in patients, consisting of 11 degrees, reflecting directly ICs multiple positive distributions.

\section{Independent prognostic factors for overall survival (OS) and relapse-free survival (RFS) in NSCLC patients}

The ICs might be related to the prognosis of cancer. In chronic lymphocytic leukemia (CLL), Kotaskova et al. (44) found that the higher expression of LAG-3 was correlated with shorter treatment-free survival, which indicated that LAG-3 was one of the novel prognostic markers in CLL. In transplantable tumor mouse models, Woo et al. (45) found that the combination therapy of anti-LAG-3 antibody and antiPD-1 antibody dramatically led to a better prognosis. MHC II was also reported as one of the independent prognostic factors for different types of cancers $(34,35,46)$. In renal cell carcinomas (RCC), Brasanac et al. (47) showed that the activation of TILs was affected by the expression of MHC II antigen, thus leading to the different prognosis of cancer. In esophageal squamous cell carcinoma, the positive expression of MHC-DR was regarded as the biomarker for tumor invasion, while the negative expression of it referred to the promoter of tumor escape $(35,48,49)$. GAL-9 and TIM-3 were also considered as a prognostic indicator for various cancers $(50,51)$. In the matter of OX40 and OX40L, the expression of OX40 on TILs was shown to be related to the survival of cancer patients, such as hepatocellular carcinoma and acute myeloid leukemia $(42,52,53)$. However, a consensus was not reached for the predictive ability of OX40 and OX40L (54).

The survival curves and outcomes of fractional variables were analyzed separately in our previous publications $(9,14,16,20,21,26)$. However, for the sake of roundly comparing OS differences among NSCLC patients in different conditions, we summed up and corrected the previous outcomes, and supplemented the missing data utilizing the Kaplan-Meier method (K-M method) (Tables S1,S2). OX40L expression 


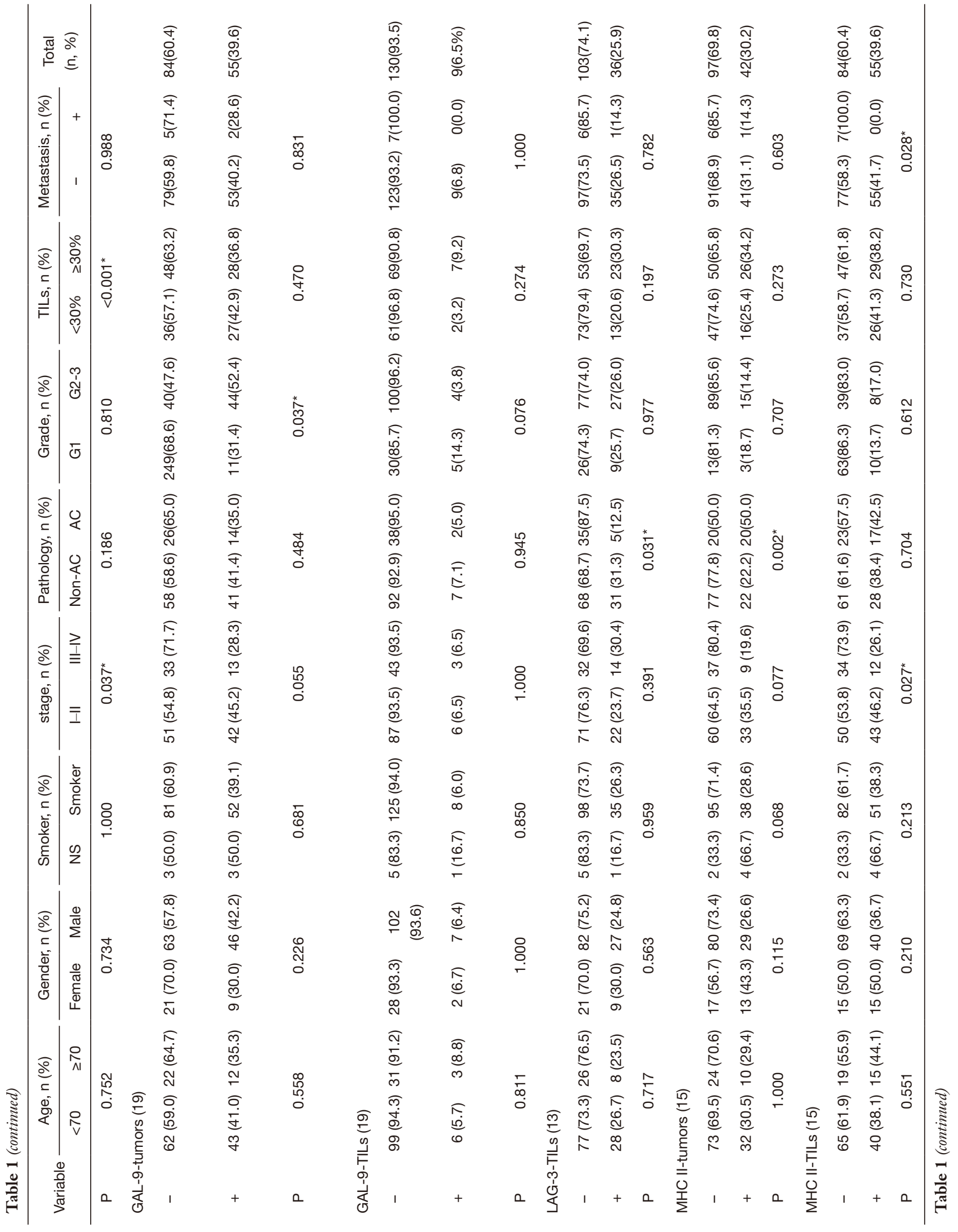


on tumors (21), GAL-9 expression on tumors (20), LAG-3 expression on TILs (14), MHC II expression on TILs (16), TIM-3 expression on TILs (26), gender, lung cancer stage, grade, and metastasis were significant independent prognostic factors for OS. Also, OX40 expression on tumors (21), MHC II expression on tumors (16), and pathology were also considered as the potential prognostic factors for OS.

Detailed information about different immunological factors as well as clinical characteristics on RFS was summarized and revised. GAL-9 expression on TILs (20), LAG-3 expression on TILs (14), MHC II expression on TILs (16), TIM-3 expression on TILs (26), lung cancer stage, grade, and metastasis were significant independent prognostic factors for RFS. In addition, OX40 expression on tumors (21), OX40L expression on tumors (21), OX40L expression on TILs (21), PD-L1 expression on tumors (9), GAL-9 expression on tumors (20), gender, and pathology were also considered as the potential prognostic factors for RFS.

\section{Conclusions}

Current guidelines emphasize the importance of accurate NSCLC sub-classifications for personalized precision medicine. Immunotherapy has a good result in lung cancer patients, and biomarkers are urgently needed to accurately sub-classify lung cancer and monitor its response.

Our review demonstrated the expression of 14 ICs on TILs and tumor cells in NSCLC and analyzed the correlations among different ICs. We also analyzed the correlation between ICs and prognosis. We found that the majority of patients were positive for multiple ICs expression, which provides a research basis for the development of bispecific and multitargeted antibodies. And the predictive value of different ICs for prognosis provides the basis for stratified precision therapy.

This landscape of ICs in NSCLC could develop promising strategies for screening for suitable patients and conferring significant survival benefits for patients. In the future, we will continue to explore the role of more targets in different pathological types of cancer to provide theoretical support for combined immunotherapy.

\section{Acknowledgments}

Funding: This study was supported in part by a grant of young talents in Shanghai, National Natural Science Foundation of China (81802255), Young Talents in Shanghai (2019QNBJ), 'Dream Tutor' Outstanding Young Talents Program (fkyq1901), Clinical Research Project of Shanghai 


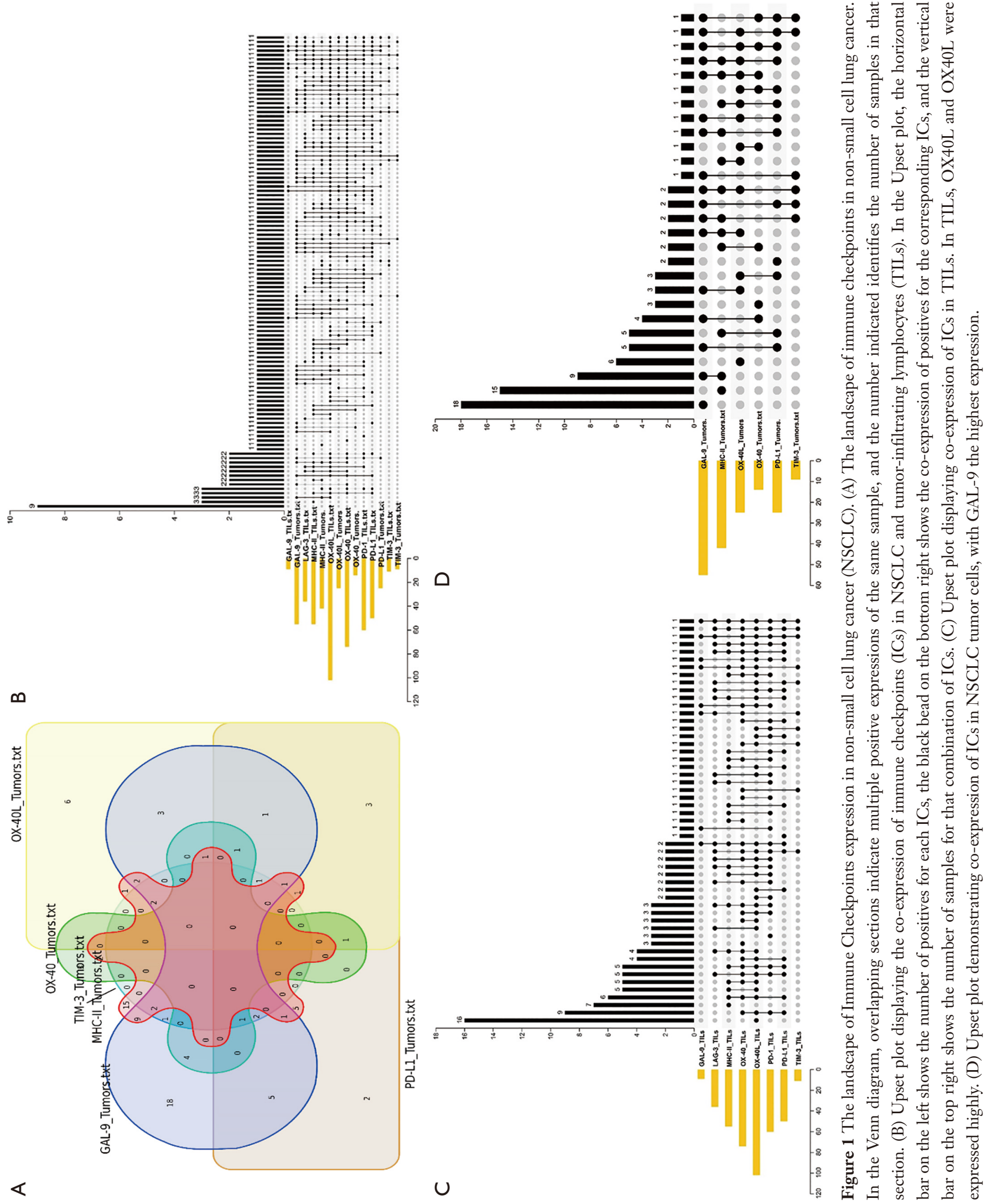


Table 2 Distribution of multiple combinations of immune checkpoints (ICs) positive patients

\begin{tabular}{lcr}
\hline Number of positive ICs & Number of patients & Percent \\
\hline 0 & 7 & $5.04 \%$ \\
$1+$ & 16 & $11.51 \%$ \\
$2+$ & 15 & $10.79 \%$ \\
$3+$ & 18 & $12.95 \%$ \\
$4+$ & 24 & $17.27 \%$ \\
$5+$ & 23 & $16.55 \%$ \\
$6+$ & 18 & $12.95 \%$ \\
$7+$ & 8 & $5.76 \%$ \\
$8+$ & 2 & $1.44 \%$ \\
$9+$ & 4 & $2.88 \%$ \\
$10+$ & 4 & $2.88 \%$ \\
Total & 139 & $100 \%$ \\
\hline
\end{tabular}

Pulmonary Hospital (fk18005), Key Discipline in 2019 (oncology), Project of Shanghai Municipal Science and Technology Commission (Project of Municipal Science and Technology Commission), Scientific research project of Shanghai Pulmonary Hospital (fkcx1903), Shanghai Municipal Commission of Health and Family Planning (2017YQ050), Innovation Training Project of SITP of Tongji University, and key projects of leading talent (19411950300).

\section{Footnote}

Reporting Checklist: The authors have completed the Narrative Review reporting checklist. Available at http:// dx.doi.org/10.21037/tlcr-20-1019

Conflicts of Interest: All authors have completed the ICMJE uniform disclosure form (Available at http://dx.doi. org/10.21037/tlcr-20-1019). The authors have no conflicts of interest to declare.

Ethical Statement: The authors are accountable for all aspects of the work in ensuring that questions related to the accuracy or integrity of any part of the work are appropriately investigated and resolved.

Open Access Statement: This is an Open Access article distributed in accordance with the Creative Commons

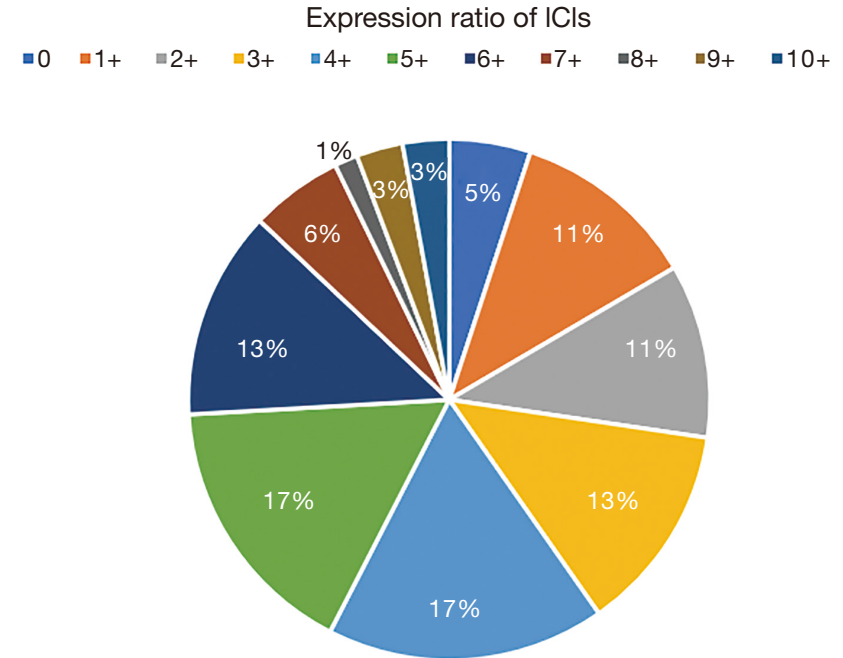

Figure 2 Distribution of multiple combinations of immune checkpoints (ICs) positive patients.

Attribution-NonCommercial-NoDerivs 4.0 International License (CC BY-NC-ND 4.0), which permits the noncommercial replication and distribution of the article with the strict proviso that no changes or edits are made and the original work is properly cited (including links to both the formal publication through the relevant DOI and the license). See: https://creativecommons.org/licenses/by-nc-nd/4.0/.

\section{References}

1. Bray F, Ferlay J, Soerjomataram I, et al. Global cancer statistics 2018: GLOBOCAN estimates of incidence and mortality worldwide for 36 cancers in 185 countries. CA Cancer J Clin 2018;68:394-424.

2. Hirsch FR, Scagliotti GV, Mulshine JL, et al. Lung cancer: current therapies and new targeted treatments. Lancet (London, England) 2017;389:299-311.

3. Scott WJ, Howington J, Feigenberg S, et al. Treatment of non-small cell lung cancer stage I and stage II: ACCP evidence-based clinical practice guidelines (2nd edition). Chest 2007;13:234S-42S.

4. Zhang QY, Wang FX, Jia KK, Kong LD. Natural Product Interventions for Chemotherapy and RadiotherapyInduced Side Effects. Front Pharmacol 2018;9:1253.

5. Corrales L, Scilla K, Caglevic C, et al. Immunotherapy in Lung Cancer: A New Age in Cancer Treatment. In: Naing A, Hajjar J. editors. Immunotherapy. Cham: Springer International Publishing, 2018:65-95. 
6. Tu L, Guan R, Yang H, et al. Assessment of the expression of the immune checkpoint molecules PD-1, CTLA4, TIM-3 and LAG-3 across different cancers in relation to treatment response, tumor-infiltrating immune cells and survival. Int J Cancer 2020;147:423-39.

7. Bremnes RM, Al-Shibli K, Donnem T, et al. The role of tumor-infiltrating immune cells and chronic inflammation at the tumor site on cancer development, progression, and prognosis: emphasis on non-small cell lung cancer. J Thorac Oncol 2011;6:824-33.

8. Wang X, Yang X, Zhang C, et al. Tumor cell-intrinsic $\mathrm{PD}-1$ receptor is a tumor suppressor and mediates resistance to PD-1 blockade therapy. Proc Natl Acad Sci U S A 2020;117:6640-50.

9. He Y, Rozeboom L, Rivard CJ, et al. PD-1, PD-L1 Protein Expression in Non-Small Cell Lung Cancer and Their Relationship with Tumor-Infiltrating Lymphocytes. Med Sci Monit 2017;23:1208-16.

10. Borghaei H, Paz-Ares L, Horn L, et al. Nivolumab versus Docetaxel in Advanced Nonsquamous Non-Small-Cell Lung Cancer. N Engl J Med 2015;373:1627-39.

11. Brahmer J, Reckamp KL, Baas P, et al. Nivolumab versus Docetaxel in Advanced Squamous-Cell Non-Small-Cell Lung Cancer. N Engl J Med 2015;373:123-35.

12. Herbst RS, Baas P, Kim DW, et al. Pembrolizumab versus docetaxel for previously treated, PD-L1-positive, advanced non-small-cell lung cancer (KEYNOTE-010): a randomised controlled trial. Lancet 2016;387:1540-50.

13. Vokes EE, Ready N, Felip E, et al. Nivolumab versus docetaxel in previously treated advanced non-small-cell lung cancer (CheckMate 017 and CheckMate 057): 3-year update and outcomes in patients with liver metastases. Ann Oncol 2018;29:959-65.

14. He Y, Yu H, Rozeboom L, et al. LAG-3 Protein Expression in Non-Small Cell Lung Cancer and Its Relationship with PD-1/PD-L1 and Tumor-Infiltrating Lymphocytes. J Thorac Oncol 2017;12:814-23.

15. Kisielow M, Kisielow J, Capoferri-Sollami G, et al. Expression of lymphocyte activation gene 3 (LAG-3) on B cells is induced by T cells. Eur J Immunol 2005;35:2081-8.

16. He Y, Rozeboom L, Rivard CJ, et al. MHC class II expression in lung cancer. Lung Cancer 2017;112:75-80.

17. Wang H, Zhao S, Zhang X, et al. Major histocompatibility complex class II molecule in non-small cell lung cancer diagnosis, prognosis and treatment. Onco Targets Ther 2019;12:7281-8.

18. Das M, Zhu C, Kuchroo VK. Tim-3 and its role in regulating anti-tumor immunity. Immunol Rev 2017;276:97-111.
19. Burugu S, Gao D, Leung S, et al. LAG-3+ tumor infiltrating lymphocytes in breast cancer: clinical correlates and association with PD-1/PD-L1+ tumors. Ann Oncol 2017;28:2977-84.

20. He Y, Jia K, Dziadziuszko R, et al. Galectin-9 in non-small cell lung cancer. Lung Cancer 2019;136:80-5.

21. He Y, Zhang X, Jia K, et al. OX40 and OX40L protein expression of tumor infiltrating lymphocytes in nonsmall cell lung cancer and its role in clinical outcome and relationships with other immune biomarkers. Transl Lung Cancer Res 2019;8:352-66.

22. Deng J, Zhao S, Zhang X, et al. OX40 (CD134) and OX40 ligand, important immune checkpoints in cancer. Onco Targets Ther 2019;12:7347-53.

23. Zhang X, He Y, Jia K, et al. Does selected immunological panel possess the value of predicting the prognosis of early-stage resectable non-small cell lung cancer? Transl Lung Cancer Res 2019;8:559-74.

24. He Y, Rivard CJ, Rozeboom L, et al. Lymphocyteactivation gene-3, an important immune checkpoint in cancer. Cancer Sci 2016;107:1193-7.

25. He Y, Cao J, Zhao C, et al. TIM-3, a promising target for cancer immunotherapy. Onco Targets Ther 2018;11:7005-9.

26. Jia K, He Y, Dziadziuszko R, et al. T cell immunoglobulin and mucin-domain containing-3 in non-small cell lung cancer. Transl Lung Cancer Res. 2019;8:895-906.

27. Huang L, Qiao G, Wu J, et al. Retracted: Expression of Lymphocyte-Activation Gene 3 (LAG-3) Immune Checkpoint Receptor Identifies a Tumor-Reactive T Cell Population in the Peripheral Blood of Patients with Colorectal Cancer. Med Sci Monit 2019;25:4400.

28. Yu X, Huang X, Chen X, et al. Characterization of a novel anti-human lymphocyte activation gene 3 (LAG-3) antibody for cancer immunotherapy. MAbs. 2019;11:1139-48.

29. Kok M. LAG-3: another brake to release in breast cancer? Ann Oncol 2017;28:2907-8.

30. Saleh R, Toor SM, Khalaf S, et al. Breast Cancer Cells and PD-1/PD-L1 Blockade Upregulate the Expression of PD1, CTLA-4, TIM-3 and LAG-3 Immune Checkpoints in CD4+ T Cells. Vaccines (Basel) 2019; 7:149.

31. Datar I, Sanmamed MF, Wang J, et al. Expression Analysis and Significance of PD-1, LAG-3, and TIM-3 in Human Non-Small Cell Lung Cancer Using Spatially Resolved and Multiparametric Single-Cell Analysis. Clin Cancer Res 2019;25:4663-73.

32. Hirschberg H, Braathen LR, Thorsby E. Antigen presentation by vascular endothelial cells and epidermal Langerhans cells: the role of HLA-DR. Immunol Rev 1982;66:57-77. 
33. Doyle A, Martin WJ, Funa K, et al. Markedly decreased expression of class I histocompatibility antigens, protein, and mRNA in human small-cell lung cancer. J Exp Med 1985;161:1135-51.

34. Sadanaga N, Kuwano H, Watanabe M, et al. Local immune response to tumor invasion in esophageal squamous cell carcinoma. The expression of human leukocyte antigen-DR and lymphocyte infiltration. Cancer 1994;74:586-91.

35. Ma XC, Hattori T, Kushima R, et al. Expression of HLAclass II antigen in gastric carcinomas. Its relationship to histopathological grade, lymphocyte infiltration and fiveyear survival rate. Acta Oncol 1994;33:187-90.

36. Foukas PG, Tsilivakos V, Zacharatos P, et al. Expression of HLA-DR is reduced in tumor infiltrating immune cells (TIICs) and regional lymph nodes of non-small-cell lung carcinomas. A putative mechanism of tumor-induced immunosuppression? Anticancer Res 2001;21:2609-15.

37. Fujita K, Iwama H, Sakamoto T, et al. Galectin-9 suppresses the growth of hepatocellular carcinoma via apoptosis in vitro and in vivo. Int J Oncol 2015;46:2419-30.

38. Kobayashi T, Kuroda J, Ashihara E, et al. Galectin-9 exhibits anti-myeloma activity through JNK and p38 MAP kinase pathways. Leukemia 2010;24:843-50.

39. Kuroda J, Yamamoto M, Nagoshi H, et al. Targeting activating transcription factor 3 by Galectin-9 induces apoptosis and overcomes various types of treatment resistance in chronic myelogenous leukemia. Mol Cancer Res 2010;8:994-1001.

40. Zhu C, Anderson AC, Schubart A, et al. The Tim-3 ligand galectin-9 negatively regulates $\mathrm{T}$ helper type 1 immunity. Nat Immunol 2005;6:1245-52.

41. Buchan SL, Rogel A, Al-Shamkhani A. The immunobiology of CD27 and OX40 and their potential as targets for cancer immunotherapy. Blood 2018;131:39-48.

42. Sawada R, Arai Y, Sagawa Y, et al. High blood levels of soluble OX40 (CD134), an immune costimulatory molecule, indicate reduced survival in patients with advanced colorectal cancer. Oncol Rep 2019;42:2057-64.

43. Chen C, Xia R, Chen H, et al. TBtools, a Toolkit for Biologists integrating various HTS-data handling tools with a user-friendly interface. bioRxiv 2018:289660.

44. Kotaskova J, Tichy B, Trbusek M, et al. High expression of lymphocyte-activation gene 3 (LAG3) in chronic lymphocytic leukemia cells is associated with unmutated immunoglobulin variable heavy chain region (IGHV) gene and reduced treatment-free survival. J Mol Diagn 2010;12:328-34.

45. Woo SR, Turnis ME, Goldberg MV, et al. Immune inhibitory molecules LAG-3 and PD-1 synergistically regulate $\mathrm{T}$-cell function to promote tumoral immune escape. Cancer Res 2012;72:917-27.

46. Redondo M, Ruiz-Cabello F, Concha A, et al. Differential expression of MHC class II genes in lung tumour cell lines. Eur J Immunogenet 1998;25:385-91.

47. Brasanac D, Markovic-Lipkovski J, Hadzi-Djokic J, et al. Immunohistochemical analysis of HLA class II antigens and tumor infiltrating mononuclear cells in renal cell carcinoma: correlation with clinical and histopathological data. Neoplasma 1999;46:173-8.

48. Kämper N, Franken S, Temme S, et al. gamma-Interferonregulated chaperone governs human lymphocyte antigen class II expression. FASEB J 2012;26:104-16.

49. Srivastava MK, Bosch JJ, Wilson AL, et al. MHC II lung cancer vaccines prime and boost tumor-specific CD4+ T cells that cross-react with multiple histologic subtypes of nonsmall cell lung cancer cells. Int J Cancer 2010;127:2612-21.

50. Qi Y, Chang Y, Wang Z, et al. Tumor-associated macrophages expressing galectin-9 identify immunoevasive subtype muscle-invasive bladder cancer with poor prognosis but favorable adjuvant chemotherapeutic response. Cancer Immunol Immunother 2019;68:2067-80.

51. Gao J, Qiu X, Li X, et al. Expression profiles and clinical value of plasma exosomal Tim-3 and Galectin-9 in nonsmall cell lung cancer. Biochem Biophys Res Commun 2018;498:409-15.

52. Xie K, Xu L, Wu H, et al. OX40 expression in hepatocellular carcinoma is associated with a distinct immune microenvironment, specific mutation signature, and poor prognosis. Oncoimmunology 2018;7:e1404214.

53. Rothfelder K, Hagelstein I, Roerden M, et al. Expression of the Immune Checkpoint Modulator OX40 in Acute Lymphoblastic Leukemia Is Associated with BCR-ABL Positivity. Neoplasia 2018;20:1150-60.

54. Lai C, August S, Albibas A, et al. OX40+ Regulatory T Cells in Cutaneous Squamous Cell Carcinoma Suppress Effector T-Cell Responses and Associate with Metastatic Potential. Clin Cancer Res 2016;22:4236-48.

Cite this article as: Liu Y, Chen P, Wang H, Wu S, Zhao S, He Y, Zhou C, Hirsch FR. The landscape of immune checkpoints expression in non-small cell lung cancer: a narrative review. Transl Lung Cancer Res 2021;10(2):1029-1038. doi: 10.21037/tlcr20-1019 
Supplementary

Table S1 Association between different variables and OS in NSCLC patients

\begin{tabular}{|c|c|c|c|c|c|c|}
\hline \multirow{2}{*}{ Variable } & \multicolumn{3}{|c|}{ Univariate } & \multicolumn{3}{|c|}{ Multivariate } \\
\hline & OS, median (years) & $95 \% \mathrm{Cl}$ & $\mathrm{P}$ & $P$ & $\mathrm{HR}$ & $95 \% \mathrm{Cl}$ \\
\hline \multicolumn{7}{|c|}{ OX40-tumors (20) } \\
\hline Negative & 2.553 (mean) & $2.220-2.886$ & 0.097 & $0.025^{\star}$ & 0.378 & $0.161-0.886$ \\
\hline Positive & 3.097 (mean) & 2.203-3.992 & & & & \\
\hline \multicolumn{7}{|c|}{ OX40-TILs (20) } \\
\hline Negative & 3.040 & $2.188-3.832$ & 0.364 & & & \\
\hline Positive & 1.720 & $0.428-3.052$ & & & & \\
\hline \multicolumn{7}{|c|}{ OX40L-tumors (20) } \\
\hline Negative & 3.040 & $2.317-3.763$ & $0.027^{*}$ & 0.741 & & \\
\hline Positive & 1.080 & $0.301-1.859$ & & & & \\
\hline \multicolumn{7}{|c|}{ OX40L-TILs (20) } \\
\hline Negative & 3.230 & $2.884-3.576$ & 0.221 & & & \\
\hline Positive & 2.140 & $0.911-3.369$ & & & & \\
\hline \multicolumn{7}{|c|}{ PD-1-TILs (8) } \\
\hline Negative & 2.290 & $1.042-3.538$ & 0.558 & & & \\
\hline Positive & 2.970 & $1.358-4.582$ & & & & \\
\hline \multicolumn{7}{|c|}{ PD-L1-tumors (8) } \\
\hline Negative & 2.960 & $2.252-3.668$ & 0.290 & & & \\
\hline Positive & 1.290 & $0.621-1.959$ & & & & \\
\hline \multicolumn{7}{|c|}{ PD-L1- TILs (8) } \\
\hline Negative & 2.090 & $0.742-3.438$ & 0.198 & & & \\
\hline Positive & 3.090 & $2.524-3.656$ & & & & \\
\hline \multicolumn{7}{|c|}{ GAL-9-tumors (19) } \\
\hline Negative & 1.690 & $0.280-3.100$ & $0.039^{\star}$ & $0.041^{*}$ & 0.620 & $0.392-0.981$ \\
\hline Positive & 3.100 & $2.662-3.583$ & & & & \\
\hline \multicolumn{7}{|l|}{ GAL-9-TILs } \\
\hline Negative & 2.790 & $1.960-3.620$ & 0.400 & & & \\
\hline Positive & 1.080 & $0.000-2.278$ & & & & \\
\hline \multicolumn{7}{|c|}{ LAG-3-TILs (13) } \\
\hline Negative & 3.040 & $2.763-3.317$ & $0.039^{*}$ & $0.005^{\star}$ & 2.005 & $1.239-3.243$ \\
\hline Positive & 1.080 & $0.419-1.742$ & & & & \\
\hline \multicolumn{7}{|c|}{ MHC II-Tumor (15) } \\
\hline Negative & 2.090 & $0.827-3.353$ & 0.083 & 0.763 & & \\
\hline Positive & 3.030 & $2.660-3.400$ & & & & \\
\hline MHC II-TILs & & & & & & \\
\hline
\end{tabular}


Table S1 (continued)

\begin{tabular}{|c|c|c|c|c|c|c|}
\hline \multirow{2}{*}{ Variable } & \multicolumn{3}{|c|}{ Univariate } & \multicolumn{3}{|c|}{ Multivariate } \\
\hline & OS, median (years) & $95 \% \mathrm{Cl}$ & $\mathrm{P}$ & $P$ & $\mathrm{HR}$ & $95 \% \mathrm{Cl}$ \\
\hline Negative & 1.390 & $0.629-2.151$ & $0.014^{*}$ & $0.024^{*}$ & 0.585 & $0.367-0.932$ \\
\hline Positive & 3.230 & $2.617-3.843$ & & & & \\
\hline \multicolumn{7}{|c|}{ TIM-3-Tumors (25) } \\
\hline Negative & 2.790 & $1.970-3.610$ & 0.615 & & & \\
\hline Positive & 1.043 & $0.000-3.505$ & & & & \\
\hline \multicolumn{7}{|l|}{ TIM-3-TILs (25) } \\
\hline Negative & 2.960 & $2.268-3.652$ & $0.034^{*}$ & 0.510 & & \\
\hline Positive & 1.080 & $0.228-1.932$ & & & & \\
\hline \multicolumn{7}{|l|}{ Age (years) } \\
\hline$<70$ & 2.290 & $1.101-3.479$ & 0.461 & & & \\
\hline$\geq 70$ & 2.980 & $1.851-4.109$ & & & & \\
\hline \multicolumn{7}{|l|}{ Gender } \\
\hline Female & 3.399(mean) & $2.688-4.111$ & $0.011^{*}$ & 0.068 & & \\
\hline Male & 2.404(mean) & $2.064-2.745$ & & & & \\
\hline \multicolumn{7}{|l|}{ Smoking status } \\
\hline Non-smoker & 1.290 & $0.006-2.574$ & 0.292 & & & \\
\hline Smoker & 2.960 & $1.915-4.005$ & & & & \\
\hline \multicolumn{7}{|l|}{ Stage } \\
\hline I-II & 3.280 & $2.865-3.695$ & $<0.001^{\star}$ & $<0.001^{*}$ & 3.437 & $2.205-5.356$ \\
\hline III-IV & 0.730 & $0.486-0.974$ & & & & \\
\hline \multicolumn{7}{|l|}{ Pathology } \\
\hline Non-AC & 2.050 & $0.871-3.229$ & 0.052 & 0.156 & & \\
\hline$A C$ & 3.230 & $2.520-3.735$ & & & & \\
\hline \multicolumn{7}{|l|}{ Grade } \\
\hline G1 & 1.390 & $0.000-2.792$ & $0.041^{*}$ & 0.364 & & \\
\hline G2-3 & 2.980 & $0.390-2.215$ & & & & \\
\hline \multicolumn{7}{|c|}{ TILs percentage } \\
\hline$<30 \%$ & 2.310 & $0.643-3.977$ & 0.568 & & & \\
\hline$\geq 30 \%$ & 2.780 & $1.692-3.868$ & & & & \\
\hline \multicolumn{7}{|l|}{ Metastasis } \\
\hline Negative & 2.970 & $2.302-3.638$ & $<0.001^{\star}$ & 0.360 & & \\
\hline Positive & 0.670 & $0.000-1.620$ & & & & \\
\hline
\end{tabular}

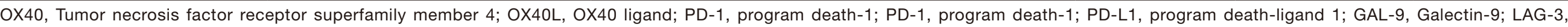

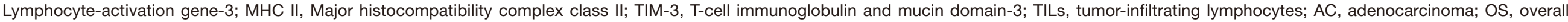
survival; $95 \% \mathrm{Cl}, 95 \%$ confidence interval; $\mathrm{HR}$, hazard ratio. *, Statistically significant $\mathrm{P}$ values. 
Table S2 Association between different variables and RFS in NSCLC patients

\begin{tabular}{|c|c|c|c|c|c|c|}
\hline \multirow{2}{*}{ Variable } & \multicolumn{3}{|c|}{ Univariate } & \multicolumn{3}{|c|}{ Multivariate } \\
\hline & RFS, median (years) & $95 \% \mathrm{Cl}$ & $P$ & $P$ & $\mathrm{HR}$ & $95 \% \mathrm{Cl}$ \\
\hline \multicolumn{7}{|c|}{ OX40-tumors (20) } \\
\hline Negative & 2.316 (mean) & $1.970-2.662$ & 0.075 & $0.045^{\star}$ & 0.470 & $0.170-0.978$ \\
\hline Positive & 3.051 (mean) & $2.139-3.971$ & & & & \\
\hline \multicolumn{7}{|c|}{ OX40-TILs (20) } \\
\hline Negative & 2.700 & $0.928-3.252$ & 0.219 & & & \\
\hline Positive & 1.410 & $1.062-1.778$ & & & & \\
\hline \multicolumn{7}{|c|}{ OX40L-tumors (20) } \\
\hline Negative & 1.910 & $0.979-2.841$ & 0.066 & 0.829 & & \\
\hline Positive & 0.890 & $0.184-1.596$ & & & & \\
\hline \multicolumn{7}{|c|}{ OX40L-TILs (20) } \\
\hline Negative & 3.190 & $2.278-3.585$ & 0.077 & $0.034^{*}$ & 1.722 & $1.043-2.842$ \\
\hline Positive & 1.420 & $0.867-1.973$ & & & & \\
\hline \multicolumn{7}{|c|}{ PD-1-TILs (8) } \\
\hline Negative & 1.760 & $1.276-2.244$ & 0.881 & & & \\
\hline Positive & 1.470 & $0.584-2.356$ & & & & \\
\hline \multicolumn{7}{|c|}{ PD-L1-tumors (8) } \\
\hline Negative & 1.850 & $0.769-2.931$ & 0.054 & 0.490 & & \\
\hline Positive & 0.970 & $0.769-1.231$ & & & & \\
\hline \multicolumn{7}{|c|}{ PD-L1- TILs (8) } \\
\hline Negative & 1.480 & $0.710-2.250$ & 0.530 & & & \\
\hline Positive & 1.760 & $0.039-3.481$ & & & & \\
\hline \multicolumn{7}{|c|}{ GAL-9-tumors (19) } \\
\hline Negative & 1.210 & $0.491-1.929$ & 0.083 & 0.064 & & \\
\hline Positive & 2.720 & $1.402-4.038$ & & & & \\
\hline \multicolumn{7}{|l|}{ GAL-9-TILs } \\
\hline Negative & 1.800 & $0.832-2.768$ & $0.036^{*}$ & $0.023^{*}$ & 2.358 & $1.127-4.933$ \\
\hline Positive & 0.670 & $0.086-1.254$ & & & & \\
\hline \multicolumn{7}{|c|}{ LAG-3-TILs (13) } \\
\hline Negative & 1.910 & $0.762-3.058$ & $0.025^{\star}$ & 0.199 & & \\
\hline Positive & 0.870 & $0.267-1.473$ & & & & \\
\hline \multicolumn{7}{|c|}{ MHC II-Tumor (15) } \\
\hline Negative & 1.470 & $0.847-2.093$ & 0.642 & & & \\
\hline Positive & 1.910 & $0.545-3.275$ & & & & \\
\hline MHC II-TILs & & & & & & \\
\hline
\end{tabular}


Table S2 (continued)

\begin{tabular}{|c|c|c|c|c|c|c|}
\hline \multirow{2}{*}{ Variable } & \multicolumn{3}{|c|}{ Univariate } & \multicolumn{3}{|c|}{ Multivariate } \\
\hline & RFS, median (years) & $95 \% \mathrm{Cl}$ & $\mathrm{P}$ & $\mathrm{P}$ & $\mathrm{HR}$ & $95 \% \mathrm{Cl}$ \\
\hline Negative & 1.050 & $0.556-1.544$ & $0.028^{\star}$ & 0.095 & & \\
\hline Positive & 2.980 & $1.638-4.332$ & & & & \\
\hline \multicolumn{7}{|c|}{ TIM-3-Tumors (25) } \\
\hline Negative & 1.760 & $1.246-2.274$ & 0.622 & & & \\
\hline Positive & 0.760 & $0.497-1.023$ & & & & \\
\hline \multicolumn{7}{|l|}{ TIM-3-TILs (25) } \\
\hline Negative & 1.800 & $1.230-2.370$ & $0.048^{\star}$ & 0.768 & & \\
\hline Positive & 0.870 & $0.212-1.528$ & & & & \\
\hline \multicolumn{7}{|l|}{ Age (years) } \\
\hline$<70$ & 1.510 & $0.916-2.104$ & 0.313 & & & \\
\hline$\geq 70$ & 2.140 & $0.000-4.283$ & & & & \\
\hline \multicolumn{7}{|l|}{ Gender } \\
\hline Female & 3.210 & $2.304-3.765$ & 0.084 & 0.551 & & \\
\hline Male & 1.470 & $0.950-1.990$ & & & & \\
\hline \multicolumn{7}{|l|}{ Smoking status } \\
\hline Non-smoker & 0.670 & $0.000-2.110$ & 0.312 & & & \\
\hline Smoker & 1.760 & $1.240-2.280$ & & & & \\
\hline \multicolumn{7}{|l|}{ Stage } \\
\hline I-II & 3.090 & $2.556-3.624$ & $<0.001^{*}$ & $<0.001^{*}$ & 3.564 & $2.308-5.504$ \\
\hline III-IV & 0.660 & $0.494-0.862$ & & & & \\
\hline \multicolumn{7}{|l|}{ Pathology } \\
\hline Non-AC & 1.420 & $0.853-1.987$ & 0.087 & 0.202 & & \\
\hline$A C$ & 2.720 & $1.341-4.099$ & & & & \\
\hline \multicolumn{7}{|l|}{ Grade } \\
\hline G1 & 1.080 & $0.802-1.358$ & $0.049^{*}$ & 0.374 & & \\
\hline G2-3 & 1.820 & $0.612-3.028$ & & & & \\
\hline \multicolumn{7}{|c|}{ TILs percentage } \\
\hline$<30 \%$ & 1.900 & $0.111-3.689$ & 0.715 & & & \\
\hline$\geq 30 \%$ & 1.690 & $1.291-2.089$ & & & & \\
\hline \multicolumn{7}{|l|}{ Metastasis } \\
\hline Negative & 1.820 & $0.882-2.758$ & $<0.001^{*}$ & 0.274 & & \\
\hline Positive & 0.470 & $0.034-0.906$ & & & & \\
\hline
\end{tabular}

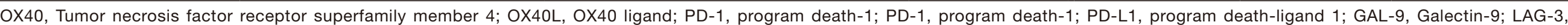

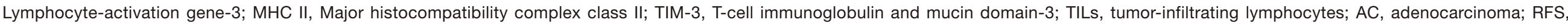
recurrence-free survival; $95 \% \mathrm{Cl}, 95 \%$ confidence interval; HR, hazard ratio. *, Statistically significant $\mathrm{P}$ values. 